\title{
Control Strategy for a SOFC Micro Gas Turbine Hybrid Power Plant Emulator Test Rig
}

\author{
A. Marcellan* and M. Hohloch*, M. Herbst*, T. Lingstädt*, T. Krummrein*, M. Henke* , and M. Aigner ${ }^{\dagger}$ \\ Institute of Combustion Technology \\ German Aerospace Center (DLR) \\ Pfaffenwaldring 38-40, 70569 Stuttgart, Germany
}

\begin{abstract}
A hybrid power plant system concept based on a $30 \mathrm{~kW}_{\mathrm{el}}$ solid oxide fuel cell (SOFC) and a $3 \mathrm{~kW}_{\mathrm{el}}$ micro gas turbine (MGT) has been developed at the German Aerospace Center (DLR). At the Institute of Combustion Technology, a test rig with a MGT and emulated SOFC has been built, in order to investigate the effects of each system on the other, and to validate the concept of the hybrid power plant before coupling the systems. A control strategy for the emulator test rig has been elaborated and tested to allow for system operation at all expected load points. Different control loops based on PI and PID controllers have been parametrized and successfully tested. A turbine outlet temperature (TOT) controller with a feed-forward element was implemented and good performance during transient maneuvers has been shown. Start-up and shut-down routines, as well as an emergency stop maneuver, have been tested and integrated into the test rig state machine.
\end{abstract}

\section{Nomenclature}

$\begin{array}{ll}\text { SOFC } & =\text { solid oxide fuel cell } \\ \text { MGT } & =\text { micro gas turbine } \\ \text { DLR } & =\text { German Aerospace Center } \\ \text { TOT } & =\text { turbine outlet temperature } \\ \text { CHP } & =\text { combined heat and power } \\ \mathrm{dp} & =\text { pressure loss } \\ \mathrm{N} & =\text { turbine rotational speed } \\ \dot{m} & =\text { mass flow } \\ \mathrm{c}_{p} & =\text { specific heat capacity } \\ \mathrm{LHV} & =\text { lower heating value } \\ \pi & =\text { pressure ratio } \\ \gamma & =\text { heat capacity ratio } \\ \eta & =\text { efficency } \\ \mathrm{PI} & =\text { proportional integral } \\ \mathrm{PID} & =\text { proportional integral derivative } \\ \mathrm{CPU} & =\text { central processing unit } \\ \mathrm{PLC} & =\text { portable logic controller } \\ \mathrm{N} & =\text { turbine rotational speed } \\ \mathrm{HIL} & =\text { hardware in the loop }\end{array}$

\section{Introduction}

A hybrid power plant with an electrical power output of $30 \mathrm{~kW}_{\mathrm{el}}$, based on the combination of a solid oxide fuel cell (SOFC) and a micro gas turbine (MGT), is a technology solution suitable for decentralized energy production that stands out among other energy systems for its high electrical efficiency and for its wide operating range relying on natural gas [1]. In this hybrid power plant concept, the SOFC uses pressurized air supplied by the compressor of the MGT to

\footnotetext{
* Research Engineer, Institute of Combustion Technology, German Aerospace Center (DLR), Stuttgart, Germany

${ }^{\dagger}$ Head of the Institute of Combustion Technology, German Aerospace Center (DLR), Stuttgart, Germany
} 
increase both power density and electric efficiency. At the same time, the MGT takes advantage of the remaining SOFC off-gas energy content to produce additional electrical power while using little or no additional fuel.

Most of the demonstrators developed thus far have operated for a limited number of hours and have not reached the maximum expected efficiency ([2], [3], [4]). Presently, only Mitsubishi Hitachi Power Systems, Ltd. (MHPS) has successfully tested and commissioned hybrid power plant demonstrators ([5], [6]). However, a detailed technical understanding of the risks and impact of the SOFC operation on the micro gas turbine and vice versa is missing. Research efforts to further investigate effective integration strategies are required. The hybrid system presents several additional constraints in comparison with a standard MGT ([1], [7]) or simple fuel cell plants. These two different technologies are based on vastly different characteristics: the very fast response of the MGT system with the low mechanical inertia of its turbine shaft, and the small thermal gradients allowed by the SOFC stack [8] due to thermal stresses. Moreover, due to the different SOFC volumes, the pressurization/depressurization time delays of anode and cathode vary. Therefore, keeping both sides at similar pressure to prevent fuel cell damage is a challenging task, especially during transient operations [9]. An integrated control system has to be developed and implemented to ensure a reliable operation of the coupled subsystems. Critical aspects essentially arising during transient operation like start-up and shut-down, load changes as well as the emergency maneuvers have to be analyzed and solved. To solve the integration issues reported above, one approach is to develop the so called "hybrid system emulators", where one of the two main components is not physically present, but emulated. In this specific case, the fuel cell stack system is not present, as it represents the most expensive and delicate system component. Such test rig represents, with different and complementary features, the layout and behavior of a real-coupled SOFC/MGT hybrid power plant, including a micro gas turbine, a fuel cell real-time simulator and all the necessary coupling elements. Therefore, the effect of a high-temperature fuel cell (SOFC) on the operating behavior of the micro gas turbine can be studied without damaging the SOFC system. The ability to develop and test the control concept on system emulators is expected to dramatically reduce the technology risk and increase the chances of success for the full prototype operation.

At the German Aerospace Center (DLR), the Combustion Technology and Engineering Thermodynamics research institutes are working together to develop a real coupled hybrid power plant test rig based on a $30 \mathrm{~kW}_{\mathrm{el}}$ solid oxide fuel cell and a $3 \mathrm{~kW}_{\mathrm{el}}$ micro gas turbine [10]. In order to investigate the effects of each system on the other and validate the concept of the coupled hybrid plant, two emulation test rigs have been built. One test rig, which includes the SOFC components and emulates the effects of the MGT system, has been developed and set up by the Institute of Engineering Thermodynamics. A second test rig, with the MGT and emulated SOFC has been developed by the Institute of Combustion Technology. Parallel works at both institutes focus on the capability of the hybrid power plant to operate with biogas. On this topic, a fuel flexible combustion system is currently investigated at the Institute of Combustion Technology [11].

This paper focuses on the development and evaluation of the control strategy for the emulator plant, which includes the micro gas turbine and a fuel cell emulator. Firstly, the emulation test rig is described in section [III] In section IV] the test rig control strategy is presented and the different control loops are discussed. The turbine speed controller setting is introduced in paragraph IV.A.1, and performance of the turbine outlet temperature controller is examined in paragraph IV.A.2. Eventually, different maneuvers and routines are discussed in section IV.B

\section{Emulation test rig}

Figure 1 shows the model of the emulator plant, and Fig. 2 its correspondent layout. In the main path, air is compressed by the MGT radial compressor and then directed into the pressure vessel simulator. A pressure vessel is used in which the volume represents the free volume of the real SOFC vessel. In the hybrid power plant, the SOFC vessel maintains the fuel cell modules under pressure and its free volume has to be consider in the emulation of the system. This is due to the relevant influence of heat and pressure losses on the system, as well as of its pressurization/depressurization dynamic. To emulate the temperature increase in the pressure vessel, an electric heater is mounted at the vessel outlet, capable of heating the air mass flow up to $670 \mathrm{~K}$. The air is then guided through the MGT recuperator, where it is heated by the hot exhaust gas exiting the turbine. After the recuperator, the air enters the cathode emulator. The SOFC cathode is emulated by a second electrical heater, which is able to heat up the air up to $1000 \mathrm{~K}$. The hot air is then directed into the combustor, where it mixes with the emulated anode exhaust gas and the reaction takes place. The anode exhaust gas composition and temperature are represented by an off-gas emulator, which consists of an $\mathrm{H}_{2}$ and $\mathrm{O}_{2}$ burner, as well as injection of $\mathrm{CO}$ and $\mathrm{CO}_{2}$ downstream of the burner. The combustion off-gas expands through the turbine, enters the hot side of the recuperator and exits the system. For start-up and shut-down purposes, the compressor outlet is also directly connected to the inlet of the pressure vessel, bypassing the recuperator. Using this bypass valve (valve 5 in Fig. 2) and 


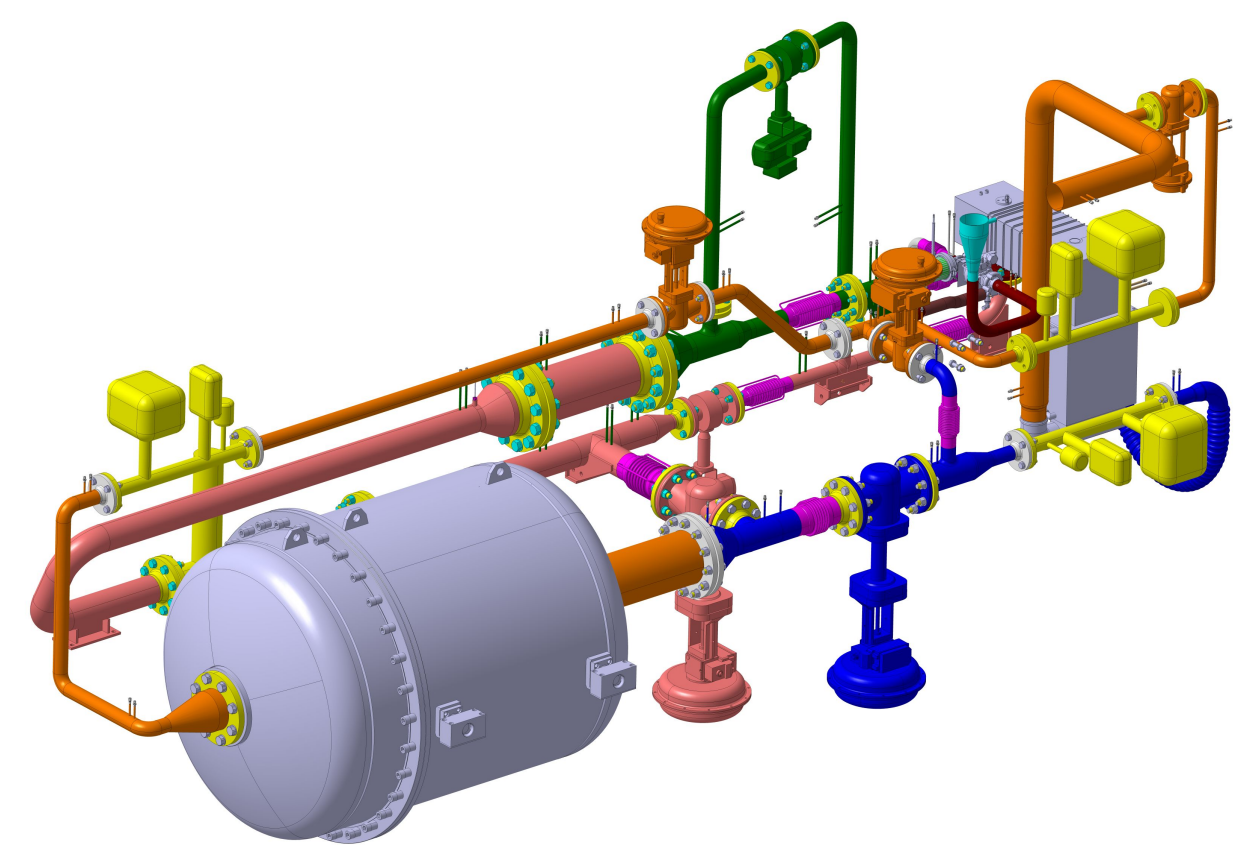

Fig. 1 Model of the MGT hybrid power plant emulation test rig piping and components, without mounting and insulation.

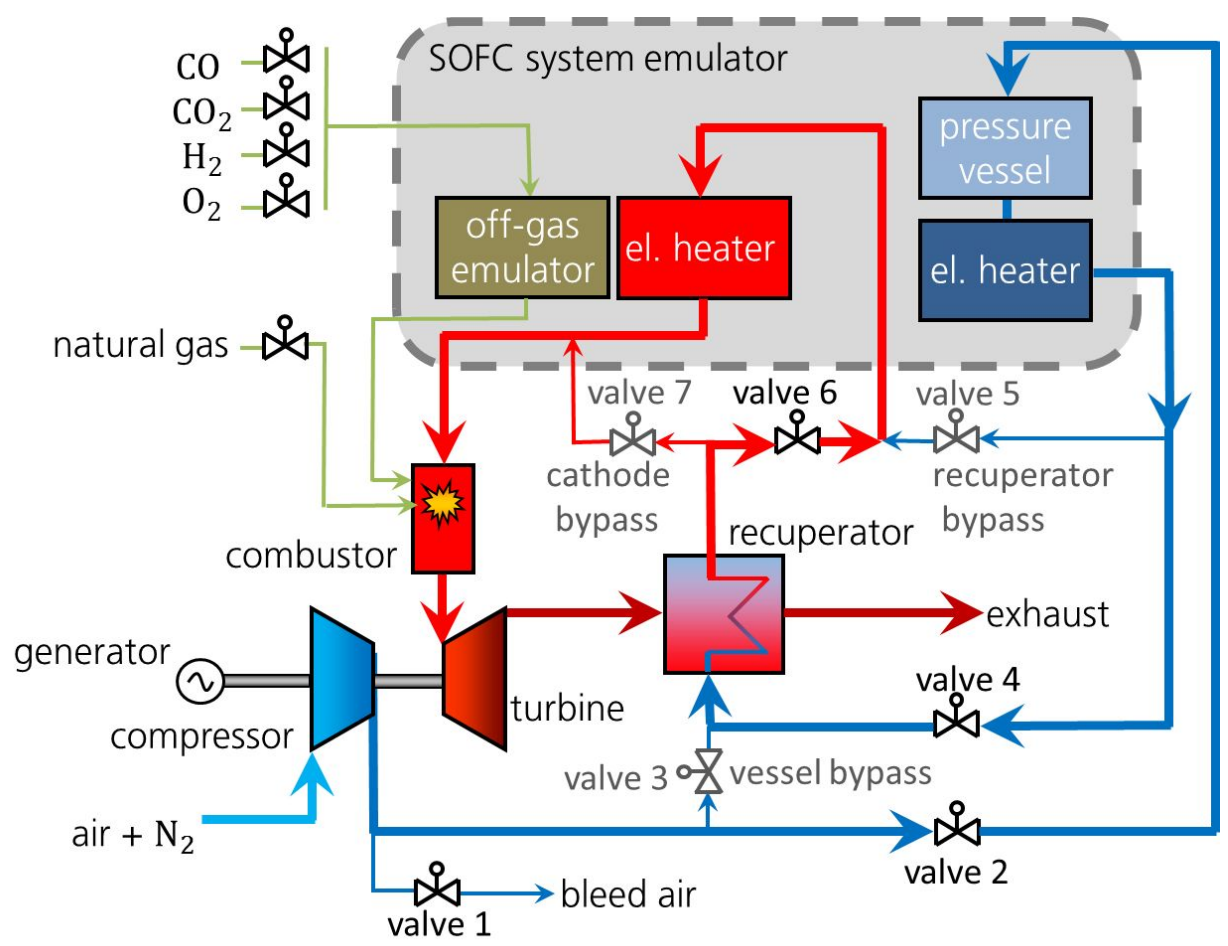

Fig. 2 MGT hybrid power plant emulation test rig layout.

the corresponding partner valve (valve 4) on the main path, the air mass flow is partly redirected, so that the SOFC inlet temperature can be adjusted to allow for small stack temperature gradients. The cathode off-gas composition is emulated by the compressor intake air dilution with $\mathrm{N}_{2}$, resulting in the estimated oxygen content reduction after the chemical reaction in the SOFC. Additional gas paths (pressure vessel emulator bypass and cathode emulator bypass) are 
included to adjust for pressure loss of the SOFC emulator components. Table 1 gives an overview on the functionality of the SOFC emulator, the utilized components and the controlled parameters.

Table 1 Emulating devices that reproduce the SOFC impact on the MGT.

\begin{tabular}{|l|l|l|}
\hline SOFC emulation & Component & Controlled parameter \\
\hline $\begin{array}{l}\text { Pressure drop and retention time through the pressure } \\
\text { vessel of the SOFC }\end{array}$ & Pressure vessel & Position of valves 2 and 3 \\
\hline $\begin{array}{l}\text { Temperature increase through the pressure vessel } \\
\text { of the SOFC }\end{array}$ & Electrical heater 1 & Temperature \\
\hline Pressure drop and retention time through the SOFC & Piping system & Position of valves 6 and 7 \\
\hline Temperature increase through the SOFC & Electrical heater 2 & Temperature \\
\hline $\begin{array}{l}\text { Gas composition and temperature at the outlet of } \\
\text { the SOFC anode (Inlet to combustion chamber) }\end{array}$ & Off-gas emulator & $\begin{array}{l}\text { Mass flow of } \mathrm{O}_{2}, \mathrm{H}_{2}, \\
\mathrm{CO}, \mathrm{CO}_{2}\end{array}$ \\
\hline $\begin{array}{l}\text { Air composition at the outlet of the SOFC cathode } \\
\text { (Inlet to combustion chamber) }\end{array}$ & $\begin{array}{l}\text { Add-on nitrogen } \\
\text { into inlet air }\end{array}$ & Mass flow of $\mathrm{N}_{2}$ \\
\hline
\end{tabular}

\section{Control strategy for the MGT emulated test rig}

In this section, the control strategy for the emulator test rig is presented. The implemented strategy is derived from the control concept for the real coupled hybrid power plant [12] and is modified for the use in the emulator test rig. The system control is based on different PI and PID controllers interconnected with each other, since the system processes are expected to have almost monotone step responses. A state machine defines different states and their mutual interactions. From the state machine, the system controllers are switched on and off and the actuators react accordingly. The software components are distributed on different platforms, where the real-time relevant programs are executed on the CPU of a portable logic controller (PLC) that communicates with the MGT control board, and all other programs run on the operator computer.

\section{A. Control loops}

In Figure 3 and Table 2, the implemented control loops are displayed and described, respectively.

1. The shaft rotational speed (control loop 1) and therefore, the air mass flow of the machine, is controlled by the original turbine manufacturer system (Micro Turbine Technology BV). However, the controller parameters and set points are given by the higher-level control system of the plant.

2. In control loop 2, a separate fuel supply provides natural gas directly to the combustion chamber, thus controlling the TOT. This controller is used mainly for start-up and shut-down maneuvers, where the SOFC is not expected to be chemically active.

3. For operation with the off-gas emulator providing the anode off-gas composition and temperature, control loop 3 adjusts the different mass flows of $\mathrm{O}_{2}, \mathrm{H}_{2}, \mathrm{CO}$ and $\mathrm{CO}_{2}$ to maintain the required TOT. For the real coupled system, the TOT will be controlled by adjusting directly the fuel mass flow to the SOFC.

4. By changing the positions of the valves of the recuperator bypass (valves 4 and $5 \mathrm{in} \mathrm{Fig.} \mathrm{2),} \mathrm{and} \mathrm{therefore} \mathrm{the} \mathrm{air}$ mass flow through the recuperator, control loop 4 regulates the air inlet temperature to the cathode.

5.- 6. Control loops 5 and 6 define the settings of the heaters to achieve the necessary vessel and cathode outlet temperatures, respectively.

7.- 8. To adjust the pressure losses throughout the cathode emulator and the vessel emulator, control loops 7 and 8 control the positions of the valves for the respective bypasses.

9. In addition, control loop 9 is implemented to detect compressor surging and react accordingly to avoid damaging of the emulator test rig. Back-flows are detected by a temperature increase at the compressor inlet. The controller opens the bleed air valve (valve 1 in Fig. 2) up to $20 \%$ of its maximal opening with a predefined ramp. As a compressor surge causes quick pressure variations and, therefore, strong mass flow fluctuations, the controller has to be improved by suitable surge precursors before implementation into the real coupled hybrid power plant. Therefore, two piezo sensors have been integrated after the compressor and before the cathode emulator. Results 
of the tests will be further analyzed to evaluate their suitability for surge detection and used to develop a controller for surge avoidance.

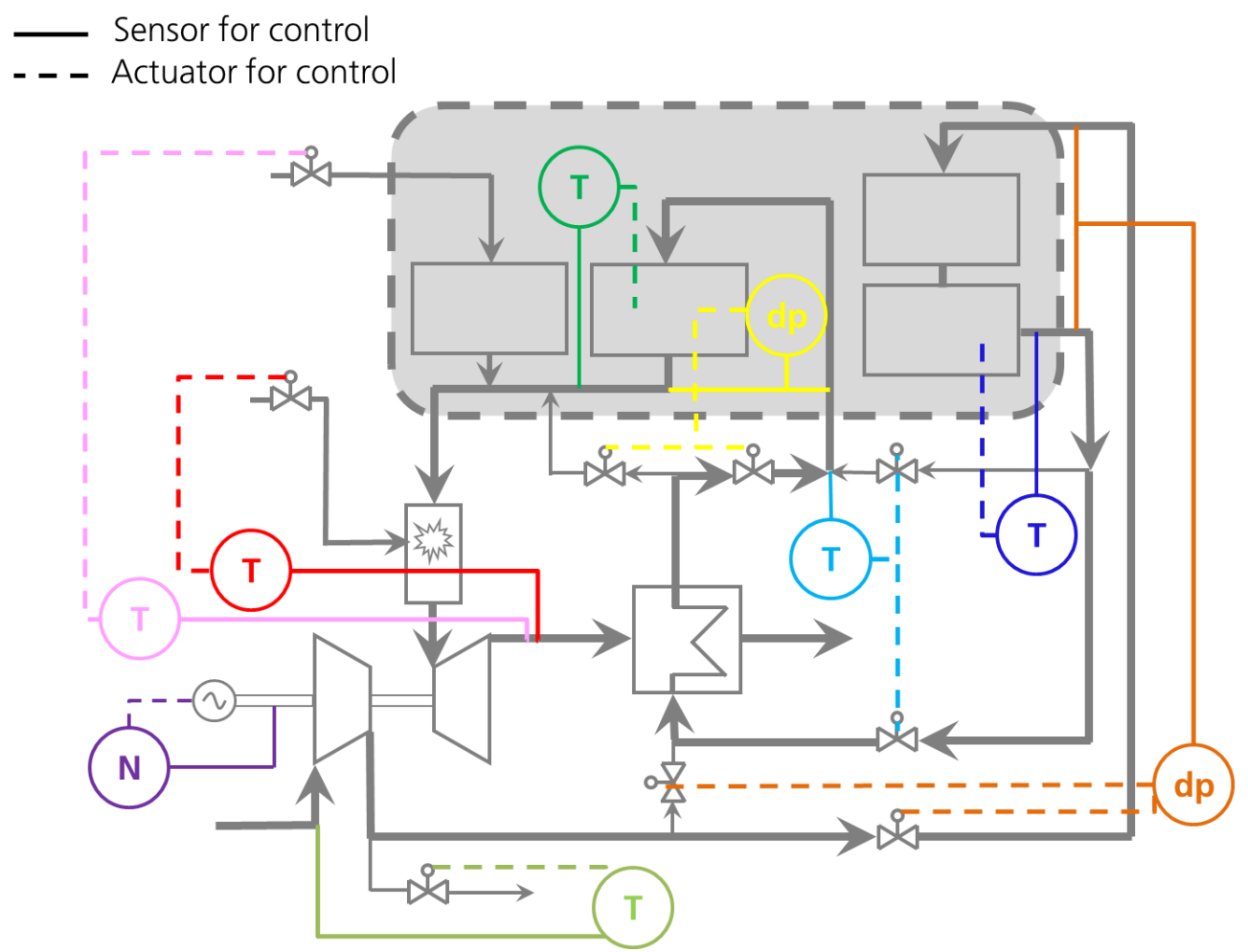

Fig. 3 Control loops of the MGT system with emulated SOFC overlayed to the plant scheme (see Fig, 2 )

Table 2 Purpose of the control loops of the MGT system with emulated SOFC.

\begin{tabular}{|l|l|l|}
\hline Number & Control loop & Color in Fig. 3 \\
\hline $\mathbf{1}$ & Turbine rotational speed & \\
\hline $\mathbf{2}$ & Turbine outlet temperature (TOT) with natural gas & \\
\hline $\mathbf{3}$ & Turbine outlet temperature (TOT) with off-gas emulator & \\
\hline $\mathbf{4}$ & Temperature at cathode emulator inlet & \\
\hline $\mathbf{5}$ & Temperature at vessel emulator outlet & \\
\hline $\mathbf{6}$ & Temperature at cathode emulator outlet & \\
\hline $\mathbf{7}$ & Pressure loss of vessel emulator & \\
\hline $\mathbf{8}$ & Pressure loss of cathode emulator & \\
\hline $\mathbf{9}$ & Temperature control at compressor inlet for surge detection & \\
\hline
\end{tabular}

The controllers for the SOFC emulation (4. to 8.) will be further adjusted using measurement data from the SOFC system. At the current state of the project, only the control loops 1, 2, 5, 6, and 9 have been implemented and tested in the plant. 


\section{Rotational speed controller settings}

Figure 4 shows the experimental results of different shaft speed PID controller parametrizations. In both Fig. 4a and Fig. 4b, the shaft is first accelerated to $90 \mathrm{krpm}$ and then kept at constant speed. In Fig. 4a, the measured rotational speed (blue curve) oscillates around the set-point (pink curve). The generator currents (green and orange curves) reach the maximum allowed start-up current value, and they can not be used to keep the rotational speed stable. When the difference between set-point and actual value remains higher than a specified limit for a certain time, the controller switches to an open-loop system. This is a type of continuous control system in which the output has no influence or effect on the control action of the input signal. In Fig. 4b a more accurate performing controller is then achieved by increasing the proportional and integral gain until an optimal value is reached. With the new gains, the controller is able to regulate the rotational speed in close-loop, as showed by the blue and pink curves matching.

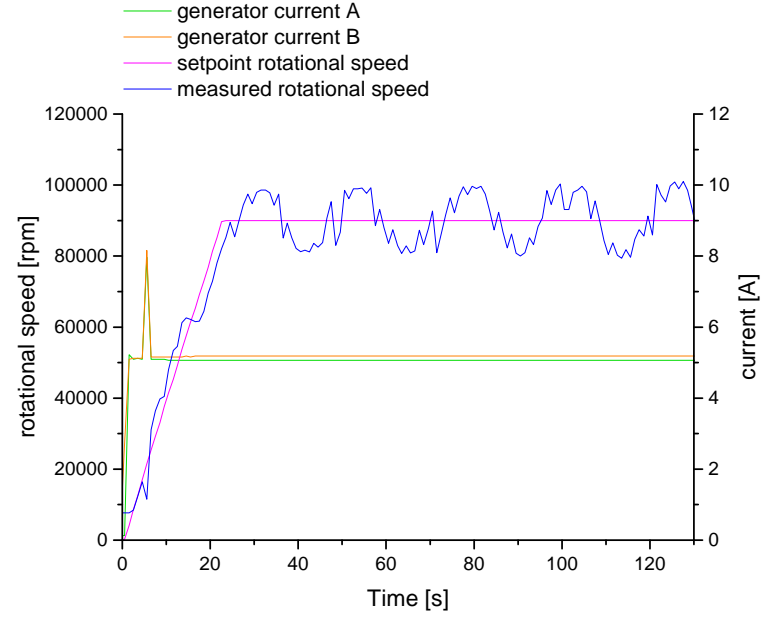

(a) Rotational speed controller with unstable response

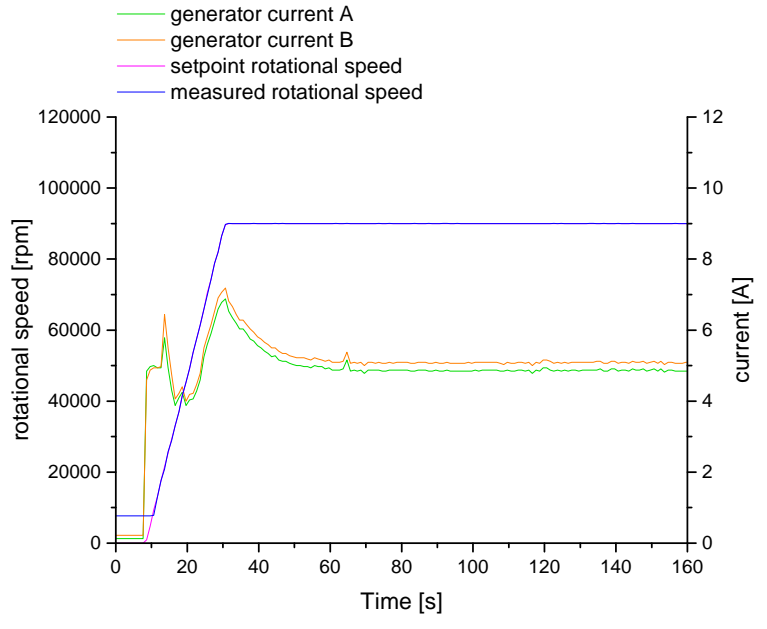

(b) Rotational speed controller after adequate parametrization

Fig. 4 Rotational speed controller experimental results.

\section{Turbine outlet temperature (TOT) controller using natural gas}

The TOT controller is crucial for the system. The thermal limit for the TOT is set, in this micro gas turbine system, to protect the turbine exhaust section and the recuperator from damage by excessive temperature. This controller will be used for the hybrid system start-up and shut-down maneuvers. Before the integration of the anode off-gas emulator, the test rig is run with natural gas, which is directly injected into the combustion chamber. Therefore, a controller is required, which constrains the TOT by adjusting the natural gas mass flow. Figure 5 shows the TOT control loop structure based on a PI controller.

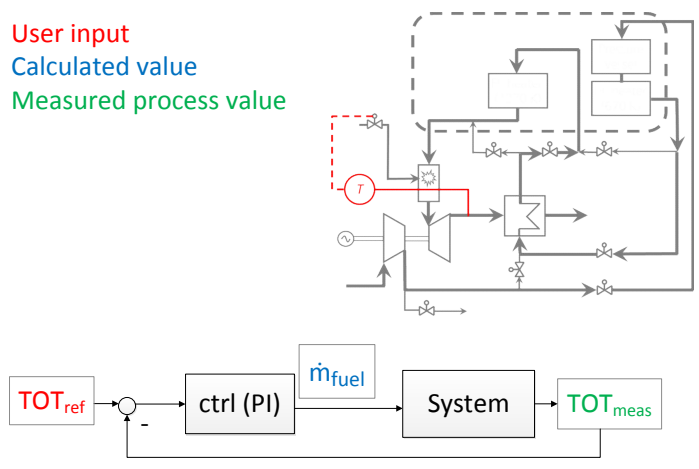

Fig. 5 TOT controller with natural gas. 


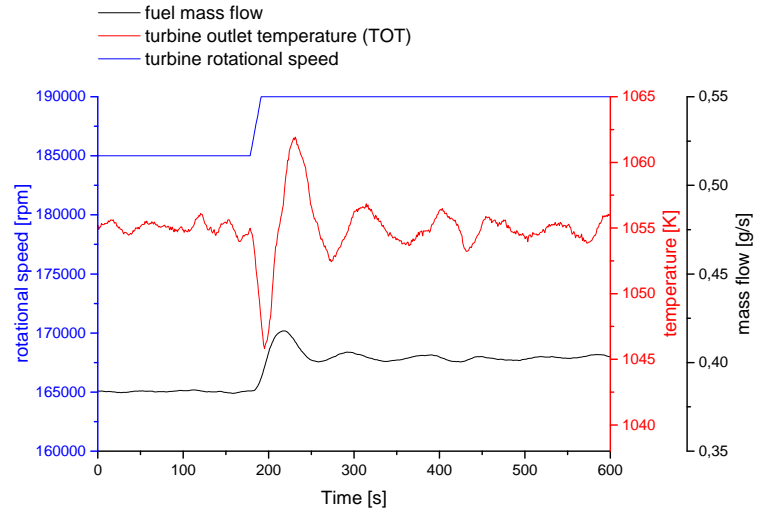

(a) TOT controller with fast but overshooting response

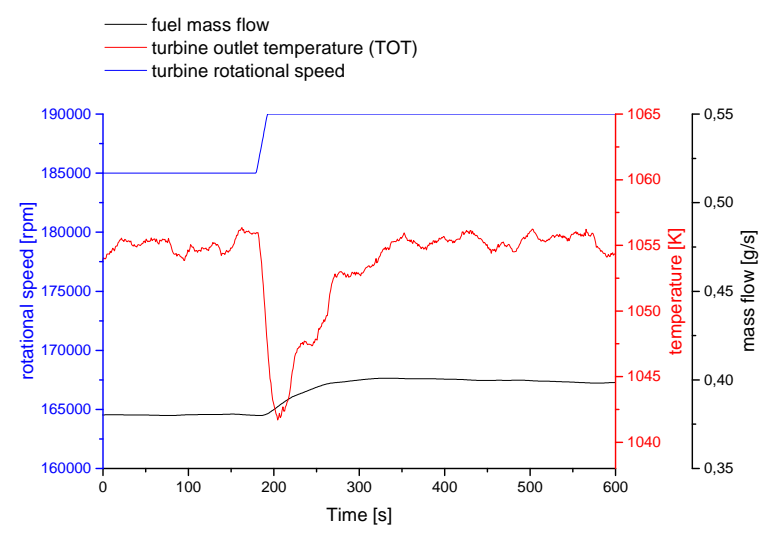

(b) TOT controller with reduced proportional gain and increased reset time

Fig. 6 Reaction to a rotational speed variation of the TOT controller with PI element

When looking at the TOT, the system behavior is affected by various parameters, such as the air mass flow, fuel mass flow and system temperature. Small fuel mass flow variations have significant effects on the TOT. Therefore, suitable parameters for a controller which must perform adequately for the entire operational range are difficult to define. Figure 6a shows the reaction of the parametrized PI controller to a rotational speed variation (blue curve). The controller reacts fast to the TOT variation (red curve) by increasing the fuel flow, represented in the graph by the black curve. However, very fast response behavior is reached at the expense of controller stability: the TOT overshoots and oscillates before settling to the desired value. Figure $6 \mathrm{~b}$ shows the reaction of the same PI controller with reduced proportional gain and increased reset time. As expected, the results indicate a stable but slow response. A slow controller can cause over-temperature at the recuperator inlet during ramp-down maneuvers, consequently damaging the component.

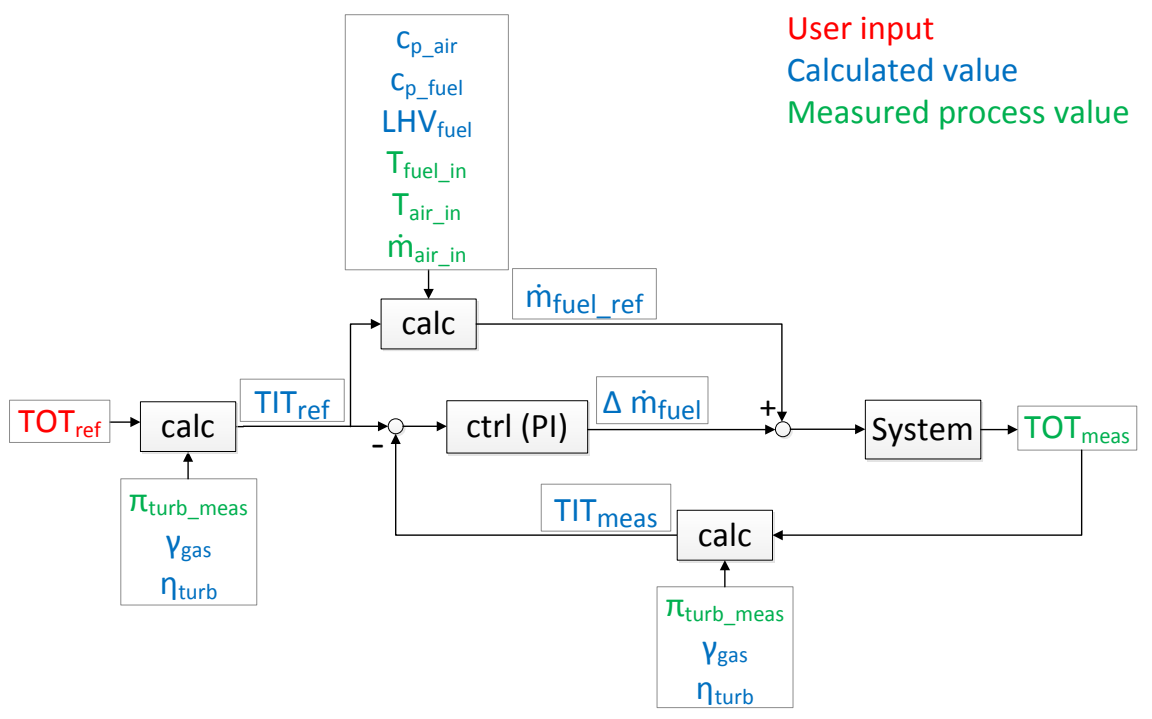

Fig. 7 TOT controller with feed-forward element.

Therefore, a feed-forward element is integrated in the control loop that estimates the fuel mass flow, based on a numerical model of the combustion chamber, as shown in Fig. 7. In a feed-forward system, the control variable adjustment is not only error-based, but also derived from the knowledge about the process and its disturbances. The PI component of the optimized control loop is a differential controller, which must adjust the calculated mass flow based 
on the difference between the actual TOT and the desired one. The benefits of the feed-forward control are significant and can often justify the extra time and effort required to implement it [13]. In this case, the feed-forward component is beneficial for a stable functioning of the system: it allows a more stable TOT behavior, which can avoid components damage in the future coupled system. Figure 8 shows the reaction of the controller with the feed-forward element. The proportional and integral gain are the same as in the simple PI control loop of Fig. 6b In comparison to the controller without feed-forward element in Fig. 6b, the controller is three times faster and the temperature overshoot is below the acceptable accuracy of 1\%. In fact, the feed-forward model predicts the mass flow variation with $80 \%$ accuracy (though exact value depends on system operating point). This percentage, and therefore the accuracy, stability and speed of the controller, can be furthermore increased with additional modeling of external disturbances and system dynamics. These will be the focus of further research with the emulator test rig.

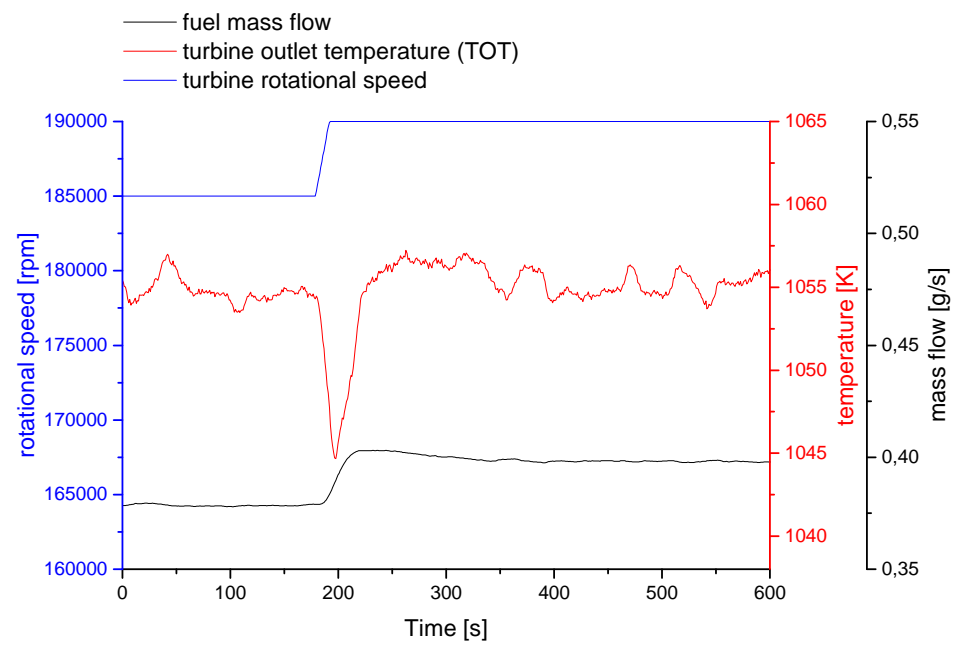

Fig. 8 TOT controller with feed-forward element reaction to a rotational speed variation.

\section{B. State Machine and maneuvers}

The state machine includes different states and defines the possible transitions between the states, Fig 9 , Every state creates set point values and operation commands for the implemented control loops. The state machine holds the state until a transition condition occurs (user input or automatic changeover). The portable logic controller (PLC) is first started via the execution of the initialization state. The connections are then checked and the system switches automatically to the "Off" state. If there are critical alarms active the system changes the state to "Emergency stop". In the "Off" state the test rig is ready for operation, however, no inputs are possible and all controllers are switched off. Next, the user can change the state to "Start-up" or to "Operation". In the "Operation" state, the user can operate all the hardware from the test equipment manually. In the "Start-up" state, the automatic start-up of the system is defined. The state consists of several routines that are executed consecutively to accelerate the shaft, ignite and approach part load. The transition from "Start-up" to "Operation" is executed automatically when the predefined shaft speed and TOT are reached. Once in the "Operation" state, different maneuvers can be performed manually or automatically. In the "Shut-down" state, the MGT system is brought to a standstill. After stopping, the state automatically changes to the "Off" state. If an emergency is detected, the "Emergency Stop" state is activated. In the real coupled system, different emergency stop maneuvers, that limit temperature and pressure gradients, will be evaluated to avoid damaging the SOFC and MGT components. For the emulation test rig with the MGT, safety of personnel is the main reason for the "Emergency Stop" state. Therefore, the focus of the maneuver is to safely stop the test rig, without permanently damaging the turbine components. 


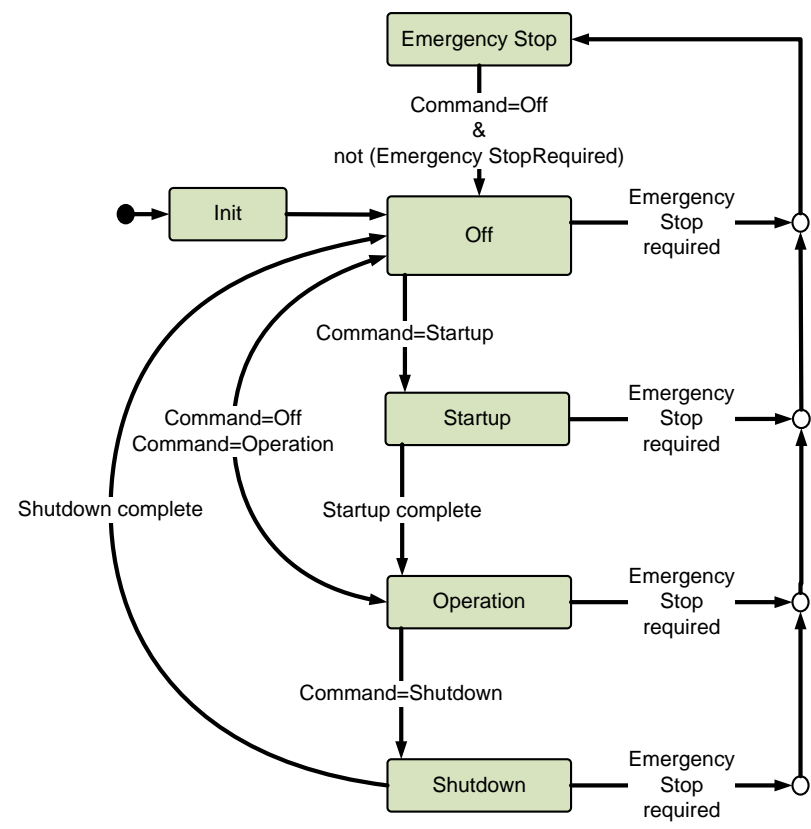

Fig. 9 State machine of the test rig.

\section{Start-up}

The start-up routine of the simple gas turbine system was adapted to the new layout of the plant. In a normal $3 \mathrm{~kW}_{\mathrm{el}}$ MGT system, the start-up maneuver consists of a quick ramp-up phase in motor mode, where the shaft is spun by the magnet and the currents from the generator, ignition, and a subsequent ramp-up phase in generator mode. The machine is then able to reach in less than an hour a "hot" steady state. Differently, the hybrid system mass is significantly higher in comparison with the simple MGT system, needing more time (up to a day) to reach a steady state. The SOFC anode and cathode are susceptible to pressure differences between components and to high temperature variations, and the larger volume between compressor and turbine increases the criticality of rapid maneuvers, as the compressor surge margin is decreased. Therefore, different routines have been first tested manually, as shown in Fig. 10a, to analyze the dynamic response of the test rig.

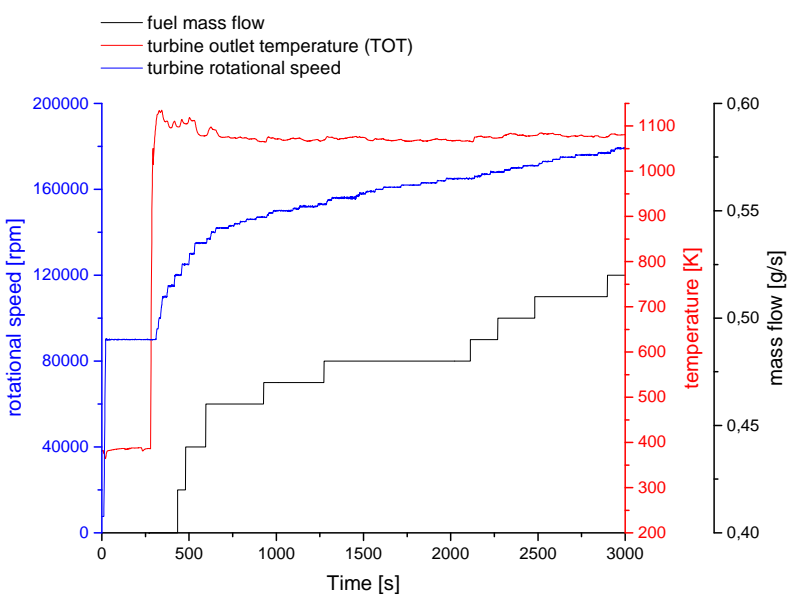

(a) Manual start-up routine

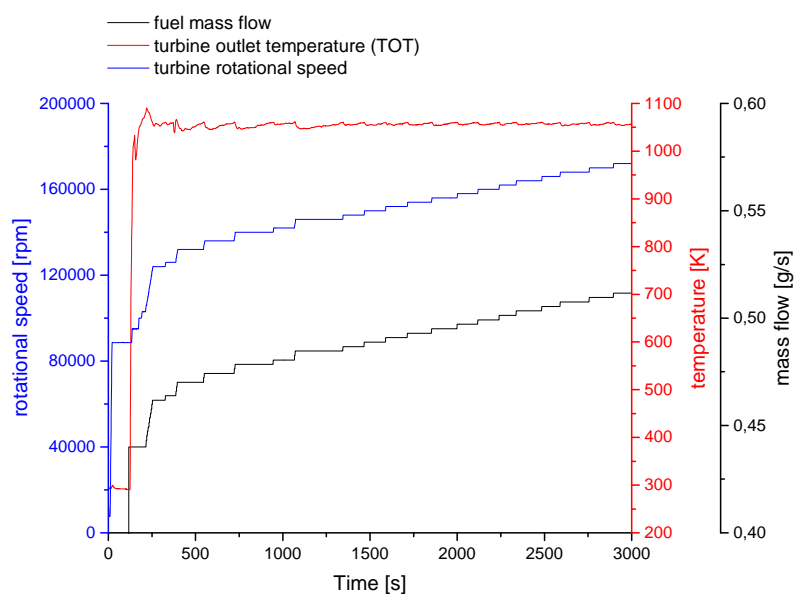

(b) Automatic start-up routine

Fig. 10 Start-up maneuvers testing.

In Fig. 10a, the shaft has first been accelerated with a fixed ramp to a predefined rotational speed suitable for ignition. 
Fuel has then been injected, and successful ignition has been recognized by a sudden TOT rise. Then, the rotational speed set-point and fuel mass flow have been manually varied in order to ramp-up the system and to keep the TOT below its maximum allowed value. From these results, a fixed automatic routine has been developed and implemented, and the performance is shown in Fig. 10b. In the automatic routine, successful ignition is determined based on the TOT gradient exceeding a defined value. A fixed empirically determined ramp-up procedure is implemented. The procedure avoids exceeding the maximum TOT, as well as preventing the system from choking (flame-out). As the acceleration ramp is adjusted, the rotational speed set-point is stepped up based on the TOT rise. The fuel mass flow rate is slowly increased according to the actual rotational speed and TOT, until the specified steady-state operational speed value is reached. The system enters then the "Operation" state, where the TOT is regulated by the closed loop PI controller.

\section{Shut-down}

The very large gas volumes between compressor and turbine of a hybrid plant generate larger depressurization delays compared to a normal MGT system. This is particularly critical during ramp-down maneuvers, where the risk of running into compressor surge is high. In a normal MGT system, the compressor pressure ratio $(\pi)$ drops with the rotational speed (N) reduction. However, in the hybrid system, the decrease in compressor pressure ratio with $\mathrm{N}$ is delayed.

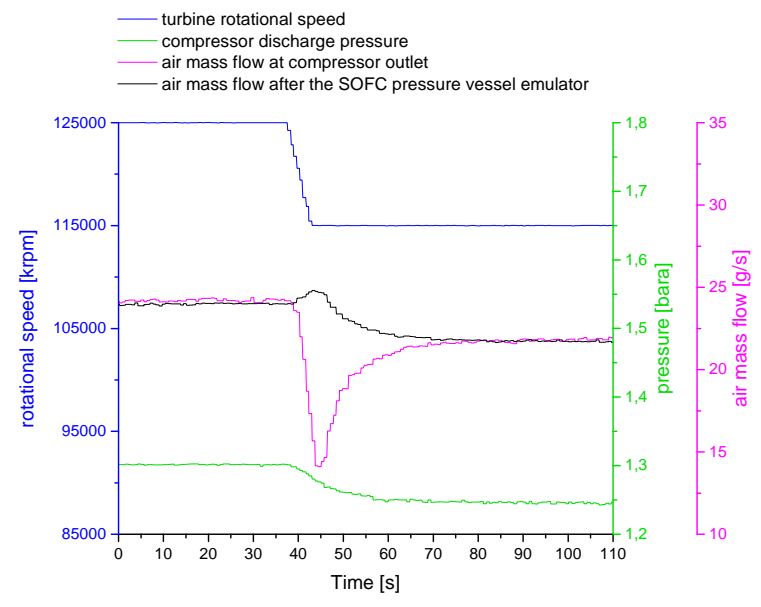

(a) Ramp-down maneuver

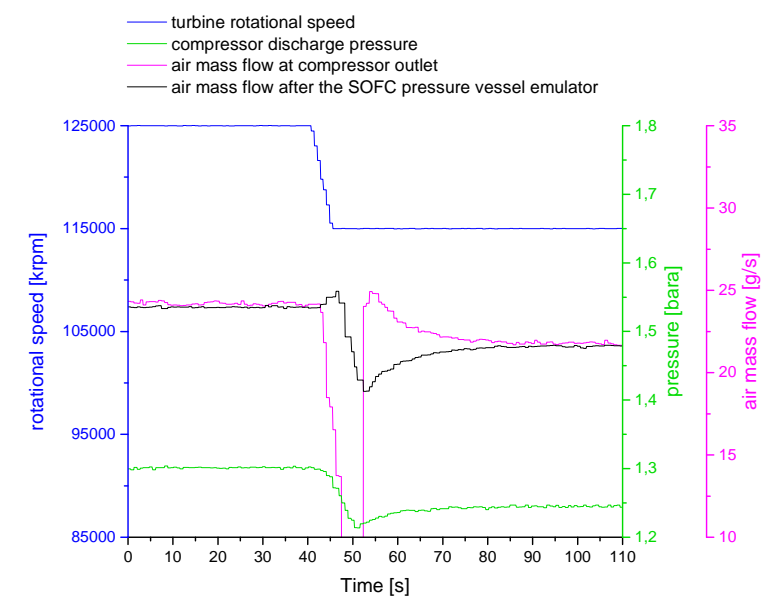

(b) Ramp-down with backflow through the compressor

Fig. 11 Effects of ramp variation during rotational speed reduction.

Figure 11 shows that a sudden drop in rotational speed causes a significant reduction in mass flow through the system, with a different dynamic for the compressor than for the turbine. The pink curve in Fig. 11a)indicates the sudden drop in compressor mass flow, while the black curve shows a smoother decrease in mass flow through the turbine, as the pressure vessel in the middle of the system acts as a buffer tank. Eventually, back-flows are possible, leading the compressor to surge as shown in Fig. 11b To avoid this detrimental behavior during shut-down, the system is first decelerated with a small ramp and with the TOT controller active, as shown in Fig. 12. As soon as the minimum steady-state MGT operational speed is reached, the fuel valve is closed and the system enters a cool-down phase. The MGT slowly switches from generator mode to motor mode. When the system reaches the specified cooled TOT, the rotational speed is further decreased to zero while the deceleration ramp is adjusted in order to avoid surging. This maneuver has been implemented as an automatic fixed maneuver in the state machine.

\section{Emergency Stop}

The emergency stop maneuver imposes a rapid transition to a turbine standstill. As explained in the previous section, quick deceleration ramps are detrimental for the turbocomponents in a system with such large volumes. To avoid damages of the test rig, the emergency stop maneuver considers the opening of the bleed air valve releasing the pressure load after the compressor and therefore increasing the compressor surge margin. Figure 13 shows the test results of the implemented routine. As soon as an emergency is detected, the fuel valve is closed (black curve). The turbine is quickly decelerated while the bleed air valve opens to $20 \%$ of its maximum (orange curve), releasing the system pressure and 
reducing the risk of back-flows. Emergency stop maneuvers suitable for a system with a real SOFC will be based on the results of the emulator test rig with a real SOFC.

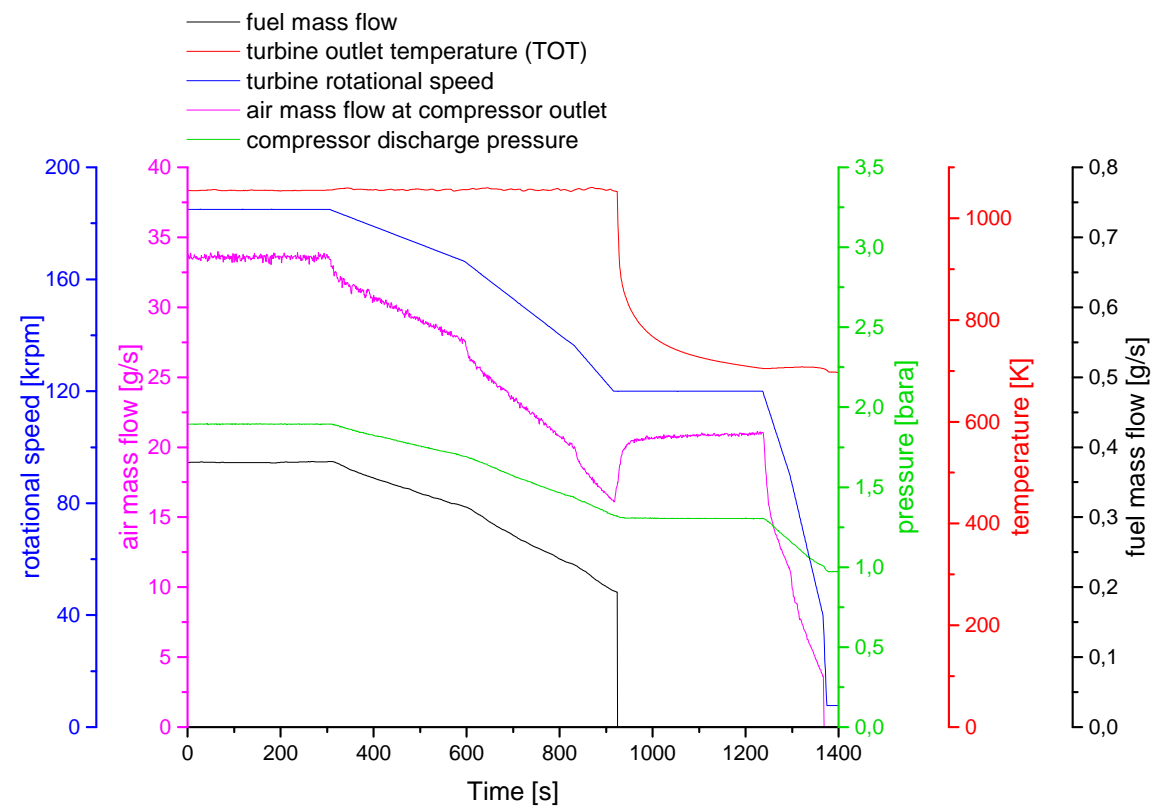

Fig. 12 Automatic shut-down routine.

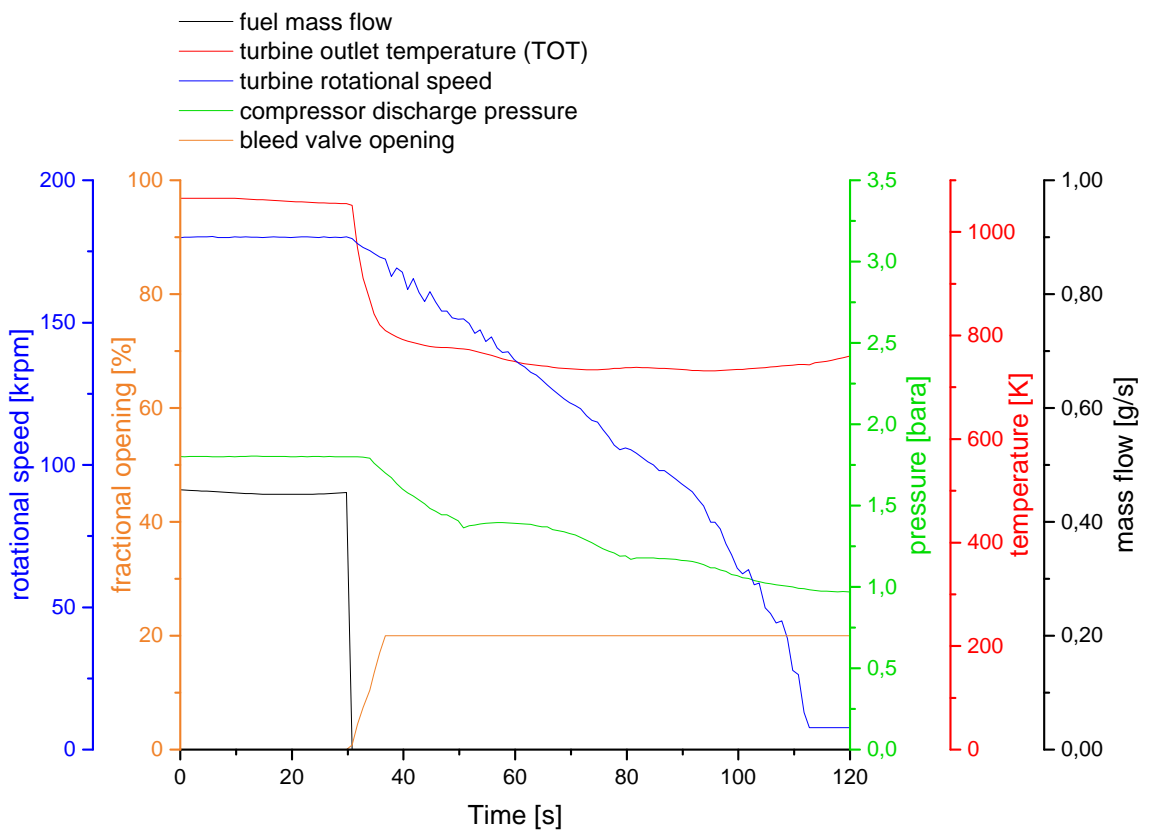

Fig. 13 Emergency Stop maneuver. 


\section{Conclusions and future works}

At the German Aerospace Center (DLR), the Institute of Combustion Technology and the Institute of Engineering Thermodynamics have developed a hybrid power plant concept based on a $30 \mathrm{~kW}_{\mathrm{el}}$ solid oxide fuel cell and a $3 \mathrm{~kW}_{\mathrm{el}}$ micro gas turbine. In order to investigate the effects of each system on the other and to validate the concept of the hybrid plant before coupling both systems, two emulation test rigs have been built. A test rig with a real MGT and emulated SOFC has been developed by the Institute of Combustion Technology. A control strategy for the emulator test rig has been implemented and tested to allow for system operation at all expected load points. Different control loops based on PI and PID controllers have been parametrized and successfully tested. A turbine outlet temperature (TOT) controller with a feed-forward element was implemented and stable performance during transient maneuvers has been shown. The influence of a higher volume between compressor and turbine component, in comparison with a normal MGT system, has been experimentally investigated. Compressor surge and back-flows have been examined, and different rotational speed ramps and their effects on system pressure variation and compressor performance have been tested. Based on these results, automatic routines have been developed and implemented in the state machine.

Next, the anode off-gas emulator will be integrated into the test-rig. Variation of turbine speed, SOFC temperature, TOT, and fuel composition will be tested. The dynamics of the SOFC will be emulated by a hardware-in-the-loop (HIL) simulation. An HIL simulation provides an effective platform by adding the complexity of the hybrid plant under investigation to the test rig. The behavior of the hybrid plant is included in the development and testing by adding a mathematical representation of all SOFC related dynamic systems. This mathematical representation is referred to as the "plant simulation". The plant simulation interacts with the MGT test rig by reading the actual system parameters,

like temperature and pressure values, and by directly controlling the SOFC emulation devices described in Tab 1 . Experimental results will be used to validate and optimize the control system for the future hybrid demonstrator.

\section{Acknowledgments}

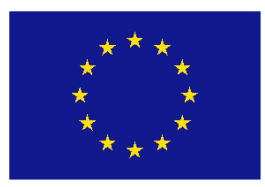

This project has received funding from the European Union's Horizon 2020 research and innovation programme under grant agreement No 641073 (www.bio-hypp.eu).

\section{References}

[1] Steilen, M., Saletti, C., Heddrich, M., and Friedrich, K. A., "Analysis of the influence of heat transfer on the stationary operation and performance of a Solid Oxide Fuel Cell/Gas Turbine hybrid power plant," Applied Energy, 2017.

[2] Veyo, S. E., Lundberg, W. L., Vora, S. D., and Litzinger, K. P., “Tubular SOFC Hybrid Power System Status,” ASME Paper No. GT2003-38943, American Society of Mechanical Engineers, 2003, pp. 649-655.

[3] Litzinger, K. P., Veyo, S. E., Shockling, L. A., and Lundberg, W. L., "Comparative Evaluation of SOFC/Gas Turbine Hybrid System Options," ASME Turbo EXPO, GT2005-68909, American Society of Mechanical Engineers, 2005, pp. 669-676.

[4] Lim, T.-H., Song, R.-H., Shin, D.-R., Yang, J.-I., Jung, H., Vinke, I., and Yang, S.-S., "Operating characteristics of a 5kW class anode-supported planar SOFC stack for a fuel cell/gas turbine hybrid system," International Journal of Hydrogen Energy, Vol. 33, 2008, p. $1076-1083$.

[5] Nishiura, M., Koga, S., Kabata, T., Hisatome, N., Kosaka, K., Ando, Y., and Kobayashi, Y., "Development of SOFC-micro gas turbine combined cycle system,” ECS Transactions, Vol. 7, No. 1, 2007, pp. 150-160.

[6] Kobayashi, Y., Ando, Y., Kabata, T., Nishiura, M., Tomida, K., and Matake, N., "Extremely high-efficiency thermal power system-solid oxide fuel cell (SOFC) triple combined-cycle system," Mitsubishi Heavy Industries Technical Review, Vol. 48, No. 3, 2011, pp. 9-15.

[7] Ferrari, M. L., and Massardo, A. F., “Cathode-anode side interaction in SOFC hybrid systems,” Applied energy, Vol. 105, 2013, pp. 369-379.

[8] McLarty, D., Brouwer, J., and Samuelsen, S., "Fuel cell-gas turbine hybrid system design part II: dynamics and control," Journal of Power Sources, Vol. 254, 2014, pp. 126-136. 
[9] Zhao, H., Dang, Z., and Xi, G., "Investigation of coupling characteristics of SOFC/MGT hybrid system," Journal of Engineering Thermophysics, Vol. 32, 2011, pp. 1647-1650.

[10] Henke, M., Steilen, M., Schnegelberger, C., Riedel, M., Hohloch, M., Bücheler, S., Herbst, M., Huber, A., Kallo, J., and Friedrich, K. A., "Construction of a 30kW SOFC Gas Turbine Hybrid Power Plant," ECS Transactions, Vol. 68, No. 1, 2015, pp. 85-88.

[11] Lingstädt, T., Grimm, F., Krummrein, T., Bücheler, S., Kutne, P., and Aigner, M., "Atmospheric Experimental Investigation of a Jet-Stabilized SOFC Off-gas Combustor for a Hybrid Power Plant operated with Biogas,” AIAA SciTech Forum, 2019.

[12] Henke, M., Steilen, M., Näke, R., Heddrich, M. P., and Friedrich, K. A., "Control strategy for a SOFC gas turbine hybrid power plant," 12th European SOFC \& SOE Forum, 2016.

[13] Seborg, D., Edgar, T., and Mellichamp, D., Process Dynamics and Control. 1989, New York: John Wiley \& Sons, 2004. 